Article

\title{
Investigating In Vitro and Ex Vivo Properties of Artemether/Lumefantrine Double-Fixed Dose Combination Lipid Matrix Tablets Prepared by Hot Fusion
}

\author{
Christi A. Wilkins, Lissinda H. du Plessis (D) and Joe M. Viljoen *(D) \\ Centre of Excellence for Pharmaceutical Sciences (PharmacenTM), Building G16, North-West University, \\ 11 Hoffman Street, Potchefstroom 2520, South Africa; christiwilkins09@gmail.com (C.A.W.); \\ Lissinda.DuPlessis@nwu.ac.za (L.H.d.P.) \\ * Correspondence: Joe.Viljoen@nwu.ac.za; Tel.: +27-(18)-2992273
}

\section{check for} updates

Citation: Wilkins, C.A.; du Plessis, L.H.; Viljoen, J.M. Investigating In Vitro and Ex Vivo Properties of Artemether/Lumefantrine Double-Fixed Dose Combination Lipid Matrix Tablets Prepared by Hot Fusion. Pharmaceutics 2021, 13, 922. https://doi.org/10.3390/ pharmaceutics13070922

Academic Editors: Beom-Jin Lee and Phuong Ha-Lien Tran

Received: 22 April 2021

Accepted: 17 May 2021

Published: 22 June 2021

Publisher's Note: MDPI stays neutral with regard to jurisdictional claims in published maps and institutional affiliations.

Copyright: (c) 2021 by the authors. Licensee MDPI, Basel, Switzerland. This article is an open access article distributed under the terms and conditions of the Creative Commons Attribution (CC BY) license (https:// creativecommons.org/licenses/by/ $4.0 /)$.
Abstract: Highly lipophilic antimalarial drugs, artemether and lumefantrine, whilst an effective fixed-dose combination treatment to lower the malarial disease burden, are therapeutically hindered by low aqueous solubility and varied bioavailability. This work investigates the plausibility of directly compressed lipid matrix tablets, their role as lipid-based formulations and their future standing as drug delivery systems. Lipid matrix tablets were manufactured from solid lipid dispersions in various lipid:drug ratios employing hot fusion-the melt mixing of highly lipophilic drugs with polymer(s). Sequential biorelevant dissolution media, multiple mathematical models and ex vivo analysis utilizing porcine tissue samples were employed to assess drug release kinetics and more accurately predict in vitro performance. Directly compressed stearic acid tablets in a 0.5:1 lipid:drug ratio were deemed optimal within investigated parameters. Biorelevant media was of immense value for artemether release analysis, with formulation SA0.5C1 (Stearic Acid:double fixed dose in a 0.5:1 ratio (i.e., Stearic acid $70 \mathrm{mg}$ + Lumefantrine $120 \mathrm{mg}$ + Artemether $20 \mathrm{mg}$ ); CombiLac ${ }^{\circledR}$ as filler (q.s.); and $1 \% \mathrm{w} / \mathrm{w}$ magnesium stearate) yielding a higher percentage of artemether release (97.21\%) than the commercially available product, $\operatorname{Coartem}^{\circledR}(86.12 \%)$. However, dissolution media lacked the specificity to detect lumefantrine. Nonetheless, stearic acid lipid:drug ratios governed drug release mechanisms. This work demonstrates the successful utilization of lipids as pharmaceutical excipients, particularly in the formulation of lipid matrix tablets to augment the dissolution of highly lipophilic drugs, and could thus potentially improve current malarial treatment regimens.

Keywords: artemether; lumefantrine; lipid-based formulations; solid lipid dispersion; hot fusion; double-fixed dose combination; biorelevant media; dissolution

\section{Introduction}

The World Health Organization has called for the use of artemisinin-based combination therapy in the fight against malaria, which accounted for an estimated 405,000 deaths globally in 2018 [1]. The Biopharmaceutics Classification System (BSC) has categorized the highly lipophilic antimalarial drugs, artemether and lumefantrine, in Class II (drugs having high permeability but low solubility). These drugs are furthermore employed as a double-fixed dose combination in a 6:1 ratio (lumefantrine:artemether) for first-line antimalarial therapy in commercial products such as Coartem ${ }^{\circledR}$ [2-4]. Overall, the therapeutic potential of highly lipophilic drugs is considerably hindered due to their low and inconsistent bioavailability arising from poor aqueous solubility. Thus, the primary challenge remains to design a dosage form capable of enhancing the solubility of these active pharmaceutical ingredients.

Low aqueous solubility can chiefly be ascribed to high intermolecular forces contained within a crystal lattice, high lipophilicity, or a combination of these elements [5]. One method implemented to augment the dissolution rate and subsequent bioavailability of 
such compounds, is hot melt extrusion. Hot melt extrusion is the process of applying heat and pressure to melt a material-for example, a polymer-which is forced through an orifice in a continuous process. It is proposed to enhance dissolution by increasing the surface area and saturation solubility [5]. Hot fusion involves heating a polymer in the absence of pressure application to the molten mass. These methods of manufacture are well suited for the preparation of lipid-based formulations (such as lipid matrix tablets) which operate on the premise that ingested exogenous lipids containing active pharmaceutical ingredients will be processed by bile salts and phospholipids into mixed micelles and colloidal species [6-10]. Thus, lipid-based formulations rely on natural physiological responses to the presence of lipids in the gastrointestinal tract (GIT) to provide a microenvironment into which lipophilic drugs may partition and subsequently be shuttled to the enterocytes of the intestinal wall for absorption [11].

Two contributing factors responsible for the intermixing of drug-polymer particles at a molecular level are the glass transition temperature of both the polymer and active pharmaceutical ingredient, as well as the melting point of said active pharmaceutical ingredient. The higher apparent solubility and increased dissolution rate for amorphous materials are extensively documented [12-16]. Their increased dissolution rates are linked to the lower thermodynamic barrier to dissolution and the formation of a glassy solution wherein the active pharmaceutical ingredient is molecularly dispersed within the polymer. The enhancement in solubility is as a result of the disordered structure of the amorphous solid. Moreover, crystalline material requires the disruption of the crystal lattice as a prerequisite for dissolution, whereas an amorphous system has short-range intermolecular interactions that require no lattice energy to be overcome. Therefore, when employing hot fusion as a method of manufacture, it is important to consider the melting point, glass transition temperature, and polymorphic behavior of the active pharmaceutical ingredients, as well as the dispersion medium selected [17].

A notable application for dissolution testing is to predict the in vivo performance of a solid oral dosage form. By identifying the limiting factor (solubility, dissolution rate or permeability), as described by the BCS, it may be possible to design a dissolution study tailored to the needs of the formulated dosage form and respective drug components $[18,19]$. Many dissolution studies are not representative of all the physiological aspects in the GIT, and the extent of inadequate aqueous solubility for BCS Class II and IV drugs is often overstated; this solubility is determined in compendial dissolution media consisting primarily of purified water and buffers. The degree of aqueous solubility is therefore misleading, as these tests do not account for the significantly higher solubilizing capacity of the human intestine as a result of the presence of bile salts [19]. Biorelevant media can more accurately predict in vivo performance, as they consider both the physiological conditions of the GIT as well as the properties of the drug and dosage form. Predictions of a dosage form's intraluminal performance requires adequate simulation of the stomach and proximal part of the small intestine, which necessitates the incorporation of gastrointestinal (GI) fluid properties, such as composition, volume, $\mathrm{pH}$, gastric emptying (particularly important for non-disintegrating systems), GI enzymes and the presence or absence of food [20]. Sunesen et al. [21] reported that compendial dissolution media often fail to yield in vitro-in vivo correlations for Class II components due to the absence of relevant physiological parameters. Therefore, concluding that, when optimizing a dissolution media's composition, it is crucial that the physiological relevance is of prime consideration, i.e., biorelevant media are utilized. Additionally, Wang et al. [22] proposed the use of biorelevant media with the incorporation of lipolytic products for lipid-based formulations, predominantly dosage forms containing BSC Class II or IV compounds, due to drug solubilization and formulation properties that have a substantial effect on the in vitroin vivo correlation. 
There are several matrix-forming materials available, depending on the properties of the drugs to be incorporated into these drug delivery systems. Thus, the physical characterization of active pharmaceutical ingredients and the selection of appropriate matrix-forming materials to be subjected to hot fusion or hot melt extrusion are vital. The lipid bases, stearic acid $\left(\mathrm{C}_{17} \mathrm{H}_{35} \mathrm{CO}_{2} \mathrm{H}\right)$, glycerol monostearate $\left(\mathrm{C}_{21} \mathrm{H}_{42} \mathrm{O}_{4}\right)$ and cetyl alcohol $\left(\mathrm{CH}_{3}\left(\mathrm{CH}_{2}\right)_{15} \mathrm{OH}\right)$ were chosen for this study, as they are all long-chain lipid bases with differing melting points and matrix-forming properties. Utilizing long-chain fatty acids enhances lymphatic uptake of lipid-based drug delivery systems, which can assist in avoiding the hepatic first-pass metabolism of an active pharmaceutical ingredient [23,24]. Findings relating to the physical characterization of these active pharmaceutical ingredients and the resulting effects of preparing solid lipid dispersions by means of hot fusion have been reported by the authors in previous work. Powder flow characterization, as well as physical observations utilizing X-ray powder diffraction studies, thermogravimetric analysis and differential scanning calorimetry, were conducted and discussed. It was concluded that hot fusion of the various lipids served only as coating of the active ingredients and did not obscure their crystallinity. Additionally, the produced solid lipid dispersions demonstrated significantly improved powder flow properties in relation to the individual active ingredients, based on an increase in overall particle size, as well as a more spherical shape. For more detail, the interested reader is referred to work by Wilkins et al. [10].

Overall, the present study built on this previous work [10] and sought to design and determine the feasibility of directly compressed lipid matrix tablets containing a doublefixed dose combination of artemether and lumefantrine. Objectives included characterizing the impact of hot fusion when manufacturing lipid matrix tablets and evaluating the biopharmaceutical behavior of the matrix system. The focus was on the relevance of biorelevant media and the resulting drug release mechanisms where, afterwards, ex vivo experiments were conducted.

\section{Materials and Methods}

\subsection{Materials}

Artemether was purchased from DB FINE CHEMICALS (Pty) Ltd. (Johannesburg, South Africa); lumefantrine was obtained from Cipla (Pty) Ltd. (Cape Town, South Africa). Stearic acid, glycerol monostearate, acetonitrile and octane-sulphonic acid were acquired from Associated Chemical Enterprises (Pty) Ltd. (Johannesburg, South Africa). Cetyl alcohol and methanol were procured from Merck (Darmstadt, Germany), and Coartem ${ }^{\circledR}$ was purchased from Novartis (Pty) Ltd. (Johannesburg, South Africa). CombiLac ${ }^{\circledR}$ and MicroceLac ${ }^{\circledR} 100$ were obtained from Meggle (Meggle Group, Wasserburg, BG Excipients \& Technology, Wasserburg, Germany). All other chemicals employed were of analytical grade.

\subsection{Preparation of Solid Lipid Dispersions Utilizing Hot Fusion}

Fixed-dose solid lipid dispersions comprising $120 \mathrm{mg}$ lumefantrine and $20 \mathrm{mg}$ artemether were prepared by means of the hot fusion method [10]. The individual lipid bases (stearic acid, glycerol monostearate or cetyl alcohol) were melted by means of continual stirring in a porcelain dish in a water bath maintained at $75^{\circ} \mathrm{C}\left( \pm 0.5^{\circ} \mathrm{C}\right)$. Active pharmaceutical ingredients, in their fixed ratios, were added to the melted lipid in a predetermined lipid:drug ratio (Table 1), and stirred until a homogenous mixture was obtained $[23,24]$. The molten mass was allowed to cool and solidify at room temperature $\left( \pm 25^{\circ} \mathrm{C}\right)$ where, afterwards, the hardened mass was manually crushed with a pestle and mortar and screened through a $595 \mu \mathrm{m}$ sieve. The resulting powdered solid lipid dispersions were individually stored at $25^{\circ} \mathrm{C}\left( \pm 0.5^{\circ} \mathrm{C}\right)$ in glass containers, sealed with Parafilm ${ }^{\circledR}$, until utilized for tablet manufacture (i.e., within $48 \mathrm{~h}$ ). 
Table 1. Factorial design of independent variables $X_{1}$ (lipid base) and $X_{3}$ (filler), and dependent variables $X_{2}$ (lipid:drug ratio) and $\mathrm{X}_{4}$ (magnesium stearate concentration), assessed during lipid matrix tablet formulation.

\begin{tabular}{|c|c|c|c|c|c|c|c|c|c|c|c|c|c|c|c|c|c|}
\hline Exp. & $X_{1}$ & $X_{2}$ & $X_{3}$ & $X_{4}$ & Code & Exp. & $X_{1}$ & $X_{2}$ & $X_{3}$ & $X_{4}$ & Code & Exp. & $X_{1}$ & $X_{2}$ & $X_{3}$ & $X_{4}$ & Code \\
\hline 1 & -1 & -1 & 0 & 0 & SA0.5C1 & 13 & 0 & -1 & 0 & 0 & GM0.5C1 & 25 & 1 & -1 & 0 & 0 & CA0.5C1 \\
\hline 2 & -1 & 0 & 0 & 0 & SA0.75C1 & 14 & 0 & 0 & 0 & 0 & GM0.75C1 & 26 & 1 & 0 & 0 & 0 & CA0.75C1 \\
\hline 3 & -1 & 1 & 0 & 0 & SA1C1 & 15 & 0 & 1 & 0 & 0 & GM1C1 & 27 & 1 & 1 & 0 & 0 & CA1C1 \\
\hline 4 & -1 & -1 & 1 & 0 & SA0.5M1 & 16 & 0 & -1 & 1 & 0 & GM0.5M1 & 28 & 1 & -1 & 1 & 0 & CA0.5M1 \\
\hline 5 & -1 & 0 & 1 & 0 & SA0.75M1 & 17 & 0 & 0 & 1 & 0 & GM0.75M1 & 29 & 1 & 0 & 1 & 0 & CA0.75M1 \\
\hline 6 & -1 & 1 & 1 & 0 & SA1M1 & 18 & 0 & 1 & 1 & 0 & GM1M1 & 30 & 1 & 1 & 1 & 0 & CA1M1 \\
\hline 7 & -1 & -1 & 0 & 1 & SA0.5C 1.25 & 19 & 0 & -1 & 0 & 1 & GM0.5C1.25 & 31 & 1 & -1 & 0 & 1 & CA0.5C 1.25 \\
\hline 8 & -1 & 0 & 0 & 1 & SA0.75C 1.25 & 20 & 0 & 0 & 0 & 1 & GM0.75C1.25 & 32 & 1 & 0 & 0 & 1 & CA0.75C1.25 \\
\hline 9 & -1 & 1 & 0 & 1 & SA1C1.25 & 21 & 0 & 1 & 0 & 1 & GM1C1.25 & 33 & 1 & 1 & 0 & 1 & CA1C1.25 \\
\hline 10 & -1 & -1 & 1 & 1 & SA0.5M1.25 & 22 & 0 & -1 & 1 & 1 & GM0.5M1.25 & 34 & 1 & -1 & 1 & 1 & CA0.5M1.25 \\
\hline 11 & -1 & 0 & 1 & 1 & SA0.75M1.25 & 23 & 0 & 0 & 1 & 1 & GM0.75M1.25 & 35 & 1 & 0 & 1 & 1 & CA0.75M1.25 \\
\hline 12 & -1 & 1 & 1 & 1 & SA1M1.25 & 24 & 0 & 1 & 1 & 1 & GM1M1.25 & 36 & 1 & 1 & 1 & 1 & CA1M1.25 \\
\hline
\end{tabular}

\subsection{Full Factorial Experimental Design}

The complete experimental design of the independent and dependent variable levels applied for this study are shown in Table 1 , where, $X_{1}$ signifies the lipid base (independent variable) and $X_{2}$ denotes the lipid:drug ratio (dependent variable) [10]. The lipid bases were assigned the following notations: stearic acid $(-1)$, glycerol monostearate $(0)$ and cetyl alcohol (1). Each of these variables were evaluated on three levels regarding the lipid:drug ratio, i.e.: 0.5:1 (low level, -1), 0.75:1 (intermediary level, 0) and 1:1 (high level, 1). Dependent variables further included filler composition $X_{3}$ : CombiLac ${ }^{\circledR}(0)$ and MicroceLac ${ }^{\circledR} 100$ (1), as well as lubricant concentration $X_{4}$ : $1 \%$ (0) or $1.25 \%$ (1).

Abbreviation codes were allocated to the combinations of factors measured to aid in-text referencing and are notated in parenthesis as follows: stearic acid (SA), glycerol monostearate (GM) and cetyl alcohol (CA). The aforementioned two-letter designation signifying the type of lipid employed as the base of the solid lipid dispersions is followed by a numerical value indicating the lipid:drug ratio as either 0.5-, 0.75- or 1-part lipid in relation to 1 part fixed-dose combination. This numerical value is subsequently followed by the first letter of the filler type (CombiLac ${ }^{\circledR}-\mathrm{C}$; MicroceLac $\left.{ }^{\circledR} 100-\mathrm{M}\right)$, followed lastly by the concentration lubricant (1 or 1.25). Consequently, the following acronym, SA0.5M1, denotes stearic acid (SA) in a 0.5:1 ratio with the fixed artemether and lumefantrine dose combination, MicroceLac ${ }^{\circledR} 100(\mathrm{M})$ as filler, and $1 \%$ magnesium stearate (MgSt).

\subsection{Preparation of Directly Compressed Tablet Formulations}

Solid lipid dispersions were prepared by weighing the respective active pharmaceutical ingredients (APIs) in the World Health Organization (WHO) approved ratio of 6:1 containing $120 \mathrm{mg}$ lumefantrine and $20 \mathrm{mg}$ artemether. The fixed dose combination was subsequently combined with a selected lipid in a corresponding lipid:drug ratio of either: $0.5: 1 ; 0.75: 1$ or 1:1. Three lipid bases namely, glycerol monostearate, stearic acid and cetyl alcohol, were investigated utilizing the previously mentioned full factorial design of experiments. All of the solid lipid dispersions were mixed with the relevant excipient combinations (Table 1) for $7 \mathrm{~min}$ in sealed glass containers using a Turbula ${ }^{\circledR}$ mixer (T2C, W.A., Bachofen AG Maschinenfabrik, Bastle, Switzerland), as per the full factorial experimental design. Powder mixtures were tableted by means of direct compression utilizing a Korsch ${ }^{\circledR}$ XP1 single station tablet press (Korsch ${ }^{\circledR}$, Berlin, Germany), $10 \mathrm{~mm}$ concave faced tableting punches (final weight of approximately $500 \mathrm{mg}$ ) and a stroke rate of 20 strokes/min.

\subsection{Pharmacotechnical Characterization}

To assess the mass variation, the individual weight of 20 randomly selected tablets for each formulation was measured on an analytical balance (Precisa ${ }^{\circledR}$, Zurich, Switzerland). Friability was performed employing a friabilator (ERWEKA ${ }^{\circledR} \mathrm{GmbH}$, Heusenstamm, Germany) according to the British Pharmacopoeia (BP) specifications [25] that states that tablets should be arbitrarily selected from a formulation to a weight as near as possible to $6.5 \mathrm{~g}$. This was approximately 10 tablets for each formulation. Disintegration testing 
was conducted on all formulations utilizing an Erweka ${ }^{\circledR}$ disintegration apparatus (model D-63150, Heusenstamm, Germany) where 6 randomly selected tablets from each formulation were tested. Following, the crushing strength, diameter, thickness and tensile strength of 10 indiscriminately selected tablets were established using a Pharma Test ${ }^{\circledR}$ tablet test unit (model PTB-311, Schlieren, Switzerland). Samples $(n=10)$ from each formulation were compressed at a rate of $0.1 \mathrm{~cm} \cdot \mathrm{min}^{-1}$. All pharmacotechnical characterization was performed in triplicate according to the BP specifications [25] for tablets with an average weight exceeding $250 \mathrm{mg}$. Acceptance criteria for all experiments were in accordance with those specified within the BP [25]. However, a minimum tablet hardness of $60 \mathrm{~N}$ [26] was deemed acceptable. Additionally, tablets that remained intact after a 15 min experimental exposure period during disintegration analyses were considered suitable, as these tablets showed signs of potential modified release, which was required for this study. Standard deviation (SD) and percentage relative standard deviation (\%RSD) were furthermore calculated where applicable. Each formulation was tested in triplicate per analysis.

\subsection{Assay}

Twenty tablets per formulation were crushed and $500 \mathrm{mg}$ was weighed from the powdered mass. Each powder sample was dissolved in $100 \mathrm{~mL} \mathrm{MeOH}$ and $1 \mathrm{~mL}$ orthophosphoric acid, and continuously stirred for $15 \mathrm{~min}$, after which it was ultrasonicated in a Labotec Ecobath ${ }^{\circledR} 103$ (Labotec, South Africa) for 20 min. The solution was filtered through a $0.45 \mu \mathrm{m}$ membrane filter and the resulting filtrate was diluted to $200 \mathrm{~mL}$. This solution was subsequently analyzed by means of high performance liquid chromatography (HPLC), as validated by Costa et al. [27], employing an Agilent 1100 HPLC system (Agilent Technologies, Santa Clara, CA, USA) equipped with a Luna C18-2 column, $150 \times 4.6 \mathrm{~mm}$, $5 \mu \mathrm{m}$ column (Phenomenex, Torrance, CA, USA). The mobile phase consisted of acetonitrile $(85 \% v / v)$ and octane-sulphonic acid $(15 \% \mathrm{v} / \mathrm{v})$ at $\mathrm{pH} 3.5$, with a flow rate of $1 \mathrm{~mL} / \mathrm{min}$ and detection wavelengths of $210 \mathrm{~nm}$ and $303 \mathrm{~nm}$ for artemether and lumefantrine, respectively. Each formulation was tested in triplicate (i.e., $n=3$ ).

\subsection{Dissolution Behavior}

The effect of the transference from gastric to intestinal $\mathrm{pH}$ on drug release was determined in sequential dissolution conditions with biorelevant media present. An initial stirring rate of $100 \mathrm{rpm}$ was set in a Distek ${ }^{\circledR}$ dissolution system (model 2500, Distek ${ }^{\circledR}$ Inc., North Brunswick, NJ, USA), connected to a Distek ${ }^{\circledR}$ Evolution 4300 auto sampler (model 4301920) and a Distek ${ }^{\circledR}$ syringe pump (SP02716), as per the BP basket method [25]. The six baskets $(n=6)$ were introduced into the medium at time zero $(t=0)$. The sequential protocol was as follows: $600 \mathrm{~mL}$ starting solution, $\mathrm{pH} 1.2$ for the first $2 \mathrm{~h}$, followed by the addition of $300 \mathrm{~mL} 0.2 \mathrm{M}$ trisodium phosphate dodecahydrate buffer $\left(\mathrm{Na}_{3} \mathrm{PO}_{4}\right), \mathrm{pH} 6.8$ for $3 \mathrm{~h}$ and, finally, the addition of $3 \mathrm{mM}$ bile salts and $0.5 \mathrm{mM}$ phospholipid at a time interval of $300 \mathrm{~min}$ for $7 \mathrm{~h}$ at a $\mathrm{pH} 7.4$ [28,29]. At predetermined time intervals $(2,5,10,20,30,60$, $90,120,150,180,240,300,390,480,600$ and $720 \mathrm{~min}$; plus, an infinity sample at $150 \mathrm{rpm}$ for $30 \mathrm{~min}$ ), withdrawn samples were analyzed by means of HPLC.

\subsection{Analysis of Drug Release Mechanism}

Artemether and lumefantrine release kinetics were evaluated using mathematical models classically employed to assess modified drug release profiles by means of DDSolver software (a freely available menu-driven add-in programme for Microsoft ${ }^{\circledR}$ Excel $^{\mathrm{TM}} 2016$ for Windows ${ }^{\mathrm{TM}}$; Microsoft ${ }^{\circledR}$ Corporation, Seattle, Washington, USA) [30]. Three selection criteria determined the goodness of fit of a model, as well as the mechanistic plausibility of the model, namely the adjusted coefficient of determination (Rsqr_adj), the Akaike Information Criterion (AIC) and Model Selection Criterion (MSC) [30,31]. Additionally, the release exponent (n) was correlated to identify the mechanism of drug release, i.e., Fickian diffusion, non-Fickian diffusion, Case II transport or Super Case II transport. For 
an in-depth understanding of the above selection criteria, the interested reader is referred to work by Zhang et al. [30].

\subsection{In Vitro Permeability Studies}

Ethical approval for the procurement of excised porcine jejunum segments from a local abattoir was obtained from the Health Research Ethics Committee, North-West University (NWU), South Africa (approval number: NWU-00369-16-A1, approval date: 07.12.2016). The serosa layer of excised porcine jejunum segments was removed by means of blunt dissection. Excised tissue was rinsed and kept moist with cold Krebs-Ringer bicarbonate (KRB) buffer for the duration of experimentation. Intestinal segments were incised along the mesenteric border, and smaller segments $(8 \mathrm{~cm} \times 2 \mathrm{~cm}$-apical side upwards) were cut and mounted onto Sweetana-Grass diffusion chamber inserts (Easy Mount Diffusion Chamber, Physiological Instruments, San Diego, CA, USA). The basolateral half-cells protocol was as follows: heating block containing $7 \mathrm{~mL} \mathrm{KRB} \mathrm{buffer} \mathrm{per} \mathrm{chamber,} \mathrm{heated}$ and maintained at $37{ }^{\circ} \mathrm{C}$, parallel gas flow $\left(5 \% \mathrm{CO}_{2}, 95 \% \mathrm{O}_{2}\right.$; flow rate: $\left.15-20 \mathrm{~mL} / \mathrm{min}\right)$, allowed $15 \mathrm{~min}$ to equilibrate. Thereafter, KRB buffer was removed from the apical chamber via aspiration with a vacuum system (Vacusafe ${ }^{\circledR}$, Hudson, NY, USA) and replaced with $7 \mathrm{~mL}$ pre-heated KRB buffer containing the dosage form to be analyzed, as well as $3 \mathrm{mM}$ bile salts and $0.5 \mathrm{mM}$ phospholipids to simulate the systemic environment.

Samples $(1 \mathrm{~mL})$ from each receiver compartment were withdrawn at 20 min intervals (duration $2 \mathrm{~h}$ ) for triplicate analysis $(n=3)$ in the apical to basolateral (AP-BL) direction. These samples were stored at $4{ }^{\circ} \mathrm{C}$ pending analysis by means of HPLC and an equivalent volume of heated media was replacement immediately. Trans-Epithelial Electrical Resistance (TEER) readings were taken directly before the addition of the lipid matrix tablets to the apical chamber, and subsequently every $20 \mathrm{~min}$ per chamber to continually evaluate tissue integrity using a Dual Channel Epithelial Voltage Clamp (Warner Instruments, Hamden, CT, USA) for the duration of the permeation study.

Ex vivo analysis involved removal of the tissue sample from the Sweetana-Grass diffusion chamber post in vitro testing. It was then rinsed with deionized water, followed by placement into a $15 \mathrm{~mL}$ glass vial containing $5 \mathrm{~mL}$ of $100 \%$ HPLC grade MeOH. Vials were mixed using a Vortex ${ }^{\circledR}$ mixer, placed in an ultrasonic bath for $10 \mathrm{~min}$ to cause lysis of the tissue, and subsequent centrifugation for $5 \mathrm{~min}$ at $3000 \mathrm{rpms}$ to separate the supernatant. Subsequently, $500 \mu \mathrm{L}$ samples were withdrawn from the supernatant and filtered $(45 \mu \mathrm{m})$ for HPLC analysis, which was performed in triplicate $(n=3)$. The percentage of active pharmaceutical ingredients present in the tissue post $120 \mathrm{~min}$ was determined and presented as percentage retention.

\subsection{Statistical Data Analysis}

The mean dissolution time (MDT), as well as fit factors [32], were calculated. Following this, the dissolution profiles of the test formulations and the control $\left(\right.$ Coartem $\left.{ }^{\circledR}\right)$ were compared and discussed according to their MDT and fit factor values. Furthermore, the fit factors concerning interrelating formulations are reported in the Supplementary Material (Table S6). The MDT indicates the average time it will take for the entire drug dose to be released from the dosage form into solution (Equation (1)).

$$
\mathrm{MDT}=\frac{\sum_{\mathrm{j}=1}^{\mathrm{n}} \mathrm{t}_{\mathrm{mid}} \Delta \mathrm{x}_{\mathrm{d}}}{\sum_{\mathrm{j}=1}^{\mathrm{n}} \Delta \mathrm{x}_{\mathrm{d}}}
$$

where $\mathrm{j}$ is the sample number; $\mathrm{n}$ is the total number of samples; $\mathrm{t}_{\mathrm{mid}}$ is midpoint time between $\mathrm{j}$ and $\mathrm{j}-1$; and $\Delta \mathrm{x}_{\mathrm{d}}$ is the additional mass of drug dissolved between $\mathrm{j}$ and $\mathrm{j}-1$.

Fit factor $f_{1}$ is the difference factor (Equation (2)) and was utilized to determine the percentage error between the two curves. Indistinguishable curves are represented by a value of 0 . Fit factor $f_{2}$ is the similarity factor (Equation (3)) between the two curves and is a logarithmic transformation of the sum of squares error. A value of $\geq 50$ indicates that 
both the test and control formulations are similar, with a value of 100 showing that the two samples are identical [33].

$$
\begin{gathered}
\mathrm{f}_{1}=\frac{\sum_{\mathrm{j}=1}^{\mathrm{n}}\left|\mathrm{R}_{\mathrm{J}}-\mathrm{T}_{\mathrm{J}}\right|}{\sum_{\mathrm{j}=1}^{\mathrm{n}}\left(\mathrm{R}_{\mathrm{J}}-\mathrm{T}_{\mathrm{J}}\right) / 2} \times 100 \\
\mathrm{f}_{2}=50 \times \log \left\{\left[1+\left(\frac{1}{\mathrm{n}}\right) \sum_{\mathrm{j}=1}^{\mathrm{n}}\left|\mathrm{R}_{\mathrm{J}}-\mathrm{T}_{\mathrm{J}}\right|^{2}\right]^{-0.5} \times 100\right\} .
\end{gathered}
$$

where $R_{J}$ is the reference assay at time point $t . T_{J}$ is the test assay at time point $t$ and $n$ is the number of pull points.

Additionally, the percentage active pharmaceutical ingredients transported across the excised intestinal tissue was plotted as a function of time, and the apparent permeability coefficient values were calculated using Equation (4) [34,35].

$$
\mathrm{P}_{\mathrm{app}}=\frac{\mathrm{dQ}}{\mathrm{dt}}\left(\frac{1}{\mathrm{~A} \cdot \mathrm{C}_{0} 60}\right)
$$

where $P_{\text {app }}$ denotes the apparent permeability coefficient $\left(\mathrm{cm} \cdot \mathrm{s}^{-1}\right)$ and $\mathrm{dQ} / \mathrm{dt}(\mu \mathrm{g} / \mathrm{s})$ represents the increase in the amount of drug in the receiver chamber within a given time period (i.e., the permeation rate as $\mu \mathrm{g} \cdot \mathrm{s}^{-1}$ ), which is equivalent to the slope of the plot of drug concentration transported versus time. A $\left(\mathrm{cm}^{2}\right)$ signifies the effective surface area of the excised porcine intestinal tissue section between the apical and basolateral chambers, and $\mathrm{C}_{0}\left(\mu \mathrm{g} \cdot \mathrm{mL}^{-1}\right)$ is the initial concentration of the specific compound present in the apical chamber.

Statistical analysis was conducted using Statistica software (ver.12; TIBCO Software Inc., New York, NY, USA). One-way analysis of variance (ANOVA) was performed, where $p$ values of $\leq 0.05$ were considered statistically significant.

\section{Results and Discussions}

\subsection{Analysis of Physical Tablet Properties}

The pharmacotechnical tablet properties of the various lipid matrix tablet formulations were researched (Supplementary Material, Tables S1-S3) and compared employing a full factorial design to assess each factor systematically and impartially. A summary table comparing all the factors evaluated at each level, and their corresponding responses per test, may be viewed in Table 2 .

Table 2. Comparison of all formulation factors investigated in the full factorial design, and their

\begin{tabular}{|c|c|c|c|c|c|c|c|}
\hline \multirow{2}{*}{ Factor } & \multicolumn{2}{|c|}{ Mass Variation } & \multirow{2}{*}{$\begin{array}{l}\text { Friability } \\
(\%)\end{array}$} & \multicolumn{2}{|c|}{ Crushing Strength } & \multicolumn{2}{|c|}{ Tensile Strength } \\
\hline & Mass (mg) & $\%$ RSD & & (N) & $\%$ RSD & $\left(\mathrm{N} \cdot \mathrm{mm}^{-2}\right)$ & $\%$ RSD \\
\hline MicroceLac ${ }^{\circledR} 100$ & 494.939 & 1.390 & 0.429 & 165.41 & 19.611 & 1.850 & 0.148 \\
\hline CombiLac $^{\circledR}$ & 494.533 & 1.710 & 0.519 & 170.56 & 20.400 & 1.978 & 0.216 \\
\hline Stearic Acid & 499.783 & 1.027 & 0.217 & 185.13 & 24.490 & 2.031 & 0.249 \\
\hline Glycerol Monostearate & 498.592 & 1.912 & 0.209 & 149.58 & 25.886 & 1.613 & 0.086 \\
\hline Cetyl Alcohol & 485.833 & 1.719 & 0.997 & 169.23 & 12.528 & 2.097 & 0.211 \\
\hline $0.5: 1$ & 495.775 & 2.088 & 0.459 & 182.25 & 11.078 & 2.084 & 0.142 \\
\hline $0.75: 1$ & 496.500 & 1.411 & 0.430 & 165.18 & 27.746 & 1.923 & 0.169 \\
\hline $1: 1$ & 491.930 & 1.158 & 0.534 & 156.51 & 21.192 & 1.735 & 0.235 \\
\hline MgSt 1\% & 497.130 & 1.411 & 0.460 & 167.99 & 20.497 & 1.914 & 0.216 \\
\hline MgSt $1.25 \%$ & 492.339 & 1.694 & 0.489 & 167.97 & 19.514 & 1.914 & 0.148 \\
\hline
\end{tabular}
corresponding responses per test, presented as an average for mass variation, friability and tensile strength results.

Analysis indicated that all formulations, regardless the lipid base employed, in combination with either MicroceLac ${ }^{\circledR} 100$ or CombiLac ${ }^{\circledR}$, produced lipid matrix tablets that overall adhered to the specified BP [25] criteria. During preformulation studies, RetaLac ${ }^{\circledR}$ and Pharmace ${ }^{\circledR} 101$ were additionally analyzed as possible fillers for inclusion in lipid 
matrix tablet formulations. However, tablets comprising these fillers lacked the required mechanical strength, and the pharmacotechnical results obtained furthermore skewed the performance characterization data of the other dependent factors. We therefore excluded reporting these results; however, relevant data are provided in the Supplementary Material (Tables S1-S3).

A prerequisite for this study was modified drug release, which was set to be achieved by the hydrophobic nature of the lipid bases employed. Thus, formulations were required to remain intact post $15 \mathrm{~min}$ disintegration testing (unlike for conventional immediate release tablets). Generally, lipid matrix tablet formulations complied with this objective due to the inclusion of a lipid base and demonstrated no other factor-dependent disintegration.

Stearic acid comprising formulations generally depicted the smallest average mass variation $(\% R S D=1.027)$, an average tensile strength of $2.031 \mathrm{~N} \cdot \mathrm{mm}^{-2}$ and satisfactorily low percentage friability $(<0.8 \%)$, whilst glycerol monostearate formulations evaluated at filler level displayed the lowest average tensile strength values (Table 2). Stearic acid is often employed as a thickening and hardening agent in the cosmetic industry, which may account for the increased tablet hardness presented as superior tensile strength in comparison to the other lipid bases. Considering all pharmacotechnical characteristics, the following general rank order could be allocated to the type of lipid bases investigated: $\mathrm{SA}>\mathrm{GM}>\mathrm{CA}$.

Comparisons of the various lipid:drug ratios and their corresponding average friability and tensile strength values yielded a distinct trend that an increase in lipid concentration caused a subsequent decrease in tensile strength and a proportional increase in percentage friability (Figure 1). This synchronous relationship between tensile strength and friability can be attributed to tablets with a higher tensile strength, i.e., with stronger interparticle forces and tighter compaction, rendering less friable tablets.

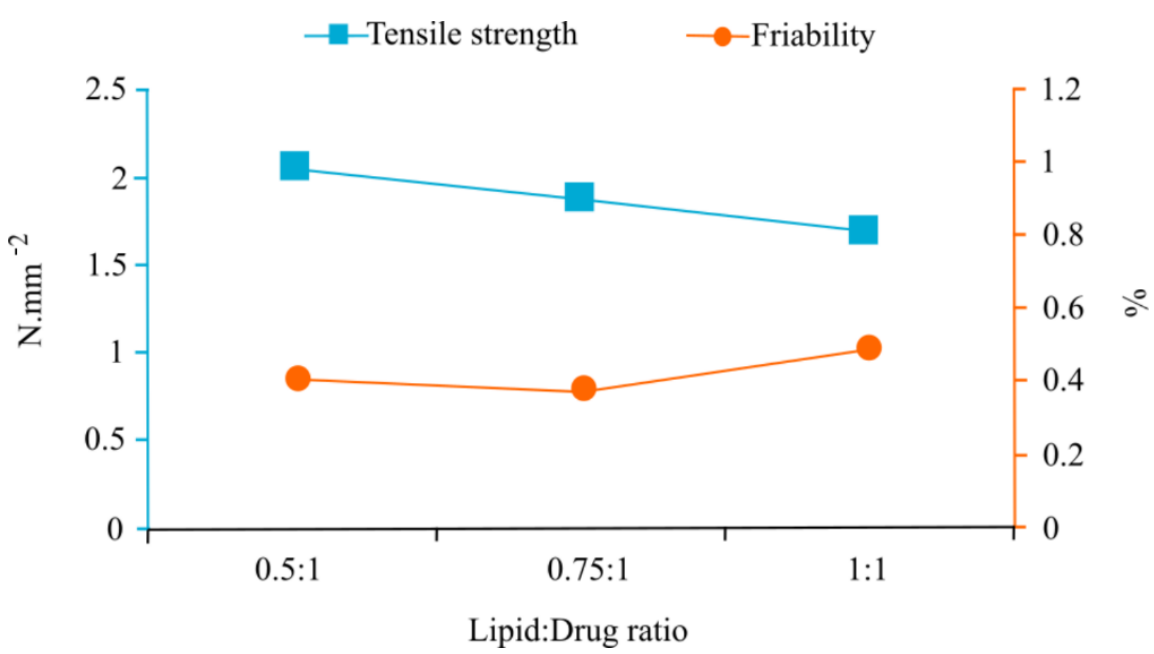

Figure 1. Dual-axis graph comparing lipid:drug ratio as a factor considering tensile strength $\left(\mathrm{N} \cdot \mathrm{mm}^{-2}\right)$ on the left $y$-axis and friability $(\%)$ on the right $y$-axis.

Moreover, the 0.5:1 lipid:drug ratio produced tablets with the highest average tensile strength $\left(2.084 \mathrm{~N} \cdot \mathrm{mm}^{-2}\right)$ and an adequately low friability $(0.459 \%)$; however, overall, it exhibited the highest average mass variation $(\% \mathrm{RSD}=2.088 \%)$. The lower lipid content dictated higher filler content to achieve the target tablet weight, which could account for the higher \%RSD-values due to the compaction properties and smaller particle size distribution of the fillers versus the solid lipid dispersions [10]. Although the 0.5:1 ratio percentage friability was in accordance with the BP standards [25], the higher tensile strength caused the tablets to be notably brittle, accounting for the higher percentage friability compared to that of the $0.75: 1$ ratio. The 1:1 ratio demonstrated the lowest tensile strength $\left(1.735 \mathrm{~N} \cdot \mathrm{mm}^{-2}\right)$ and the highest percentage friability, implying that the reduction 
in tablet hardness caused these formulations to be more friable. Friability is a measure of a tablet's resistance to abrasion during packaging, transportation and handling, and is strongly correlated with compression force. Highly friable tablets often relate to a low compression force, resulting in weak bonding between adjacent particles. Particles in closer proximity to one another form stronger bonds, and therefore have increased mechanical strength [36]. Pertaining to the pharmacotechnical characteristics obtained for the investigated lipid:drug ratios, the following ranking was assigned: 0.75:1 $\geq 0.5: 1>1: 1$.

Magnesium stearate was included to aid the compaction process due to its ability to reduce wall friction during tablet ejection [37], improve powder flow [38] and reduce the risk of pharmaceutical formulations adhering to exposed metal surfaces during tableting $[39,40]$. Formulations containing $0 \%$ magnesium stearate adhered to the tablet punches during tableting, resulting in a non-uniform appearance and tablet weight (preformulation research). Furthermore, there was no substantial difference in tablet characteristics, regardless of the inclusion of magnesium stearate, at two different levels (1\% and 1.25\%). All formulations containing either $1 \%$ or $1.25 \%$ magnesium stearate produced acceptable average \%RSD-values of $1.411 \%$ and $1.694 \%$, respectively, for mass variation, and yielded no noticeable differences in the internal or external morphology of manufactured tablets (Supplementary Material, Table S4 and Figures S1-S4). However, an increase in magnesium stearate concentration did result in an increase in \%RSD-values and an even more pronounced increase in the percentage of friability. The occurrence of an increase in magnesium stearate concentrations, rendering decreased tablet hardness and increased friability, is well documented [37,41-44]. Additionally, an equal average tensile strength of $1.914 \mathrm{~N} \cdot \mathrm{mm}^{-2}$ was achieved when evaluating magnesium stearate concentration as a factor (Table 2), which suggests that the difference in magnesium stearate concentration was insufficient to produce a significant variance in response when assessed at filler and lipid:drug ratio level. For these reasons, 1\% magnesium stearate was identified as the lowest functioning lubricant concentration necessary to produce acceptable lipid matrix tablets in this study.

\subsection{Assay}

Artemether and lumefantrine content was analyzed for each formulation (Supplementary Material, Table S5). To be able to ascertain whether noticeable differences were present, a summary table of average artemether and lumefantrine content per factor was constructed (Table 3).

Table 3. Percentage of active pharmaceutical ingredient (API) content, presented as an average per factor evaluated.

\begin{tabular}{cccc}
\hline \multirow{2}{*}{ Factor } & Variable & \multicolumn{2}{c}{ API Content (\%) } \\
\cline { 3 - 4 } & & Artemether & Lumefantrine \\
\hline \multirow{2}{*}{ Lipid type } & Stearic acid & 85.56 & 111.94 \\
& Glycerol monostearate & 83.62 & 92.52 \\
& Cetyl alcohol & 87.26 & 96.67 \\
\hline \multirow{2}{*}{ Filler type } & MicroceLac $^{\circledR} 100$ & 90.42 & 104.34 \\
& CombiLac $^{\circledR}$ & 80.55 & 96.41 \\
\hline \multirow{2}{*}{ Lipid:drug ratio } & $0.5: 1$ & 97.58 & 107.20 \\
& $0.75: 1$ & 79.72 & 106.22 \\
& $1: 1$ & 79.14 & 87.71 \\
\hline
\end{tabular}

No conspicuous differences were detected between the various lipid bases for artemether content. However, when stearic acid was employed, lumefantrine content was deliberated as the highest when comparing lipid bases. MicroceLac ${ }^{\circledR} 100$ formulations overall depicted slightly higher active pharmaceutical ingredient content for both active ingredients. The 0.5:1 lipid:drug ratio similarly displayed a higher drug content for both active pharmaceuti- 
cal ingredients, whereas the 1:1 ratio exhibited the lowest active pharmaceutical ingredient content of the three ratios investigated. Thus, as lipid concentration increased, the overall active pharmaceutical ingredient content appeared to decrease.

The overall trend observed revealed that the percentage of artemether content obtained was typically lower than the theoretical content whilst, in comparison, a noticeably higher percentage of lumefantrine content was demonstrated. The variance in target content may have resulted from loss of active pharmaceutical ingredients due to dust formation during post-hot fusion processing of solid lipid dispersions and lipid matrix tablet manufacture.

\subsection{Dissolution Behavior}

Stearic acid-containing lipid matrix tablet formulations displayed a lipid:drug ratiodependent artemether release trend (Figure 2a). Moreover, the 0.5:1 ratio, regardless of the filler, fitted the Korsmeyer-Peppas with $\mathrm{T}_{\text {lag }}$ model, which is indicative of Fickian diffusion ( $n$-value $<0.45)$. The 0.75:1 ratio fitted the Peppas-Sahlin1 with $\mathrm{T}_{\text {lag }}$ model, consistent with non-Fickian diffusion that entails a diffusion rate higher than or equal to the rate of polymer relaxation. Finally, the 1:1 ratio conformed to the Peppas-Sahlin2, with the $\mathrm{T}_{\text {lag }}$ model demonstrating the drug transport mechanism was controlled by both Fickian diffusion and Case II relaxation.

SA0.5C1 was identified as the optimal formulation in this study regarding artemether release (97.21\% of theoretical content), and was compared to the artemether dissolution results achieved from Coartem $^{\circledR}$ tablets $(86.12 \%$ artemether pharmaceutically available). Statistically relevant differences between the lipid:drug ratios $\left(f_{1}\right.$ - and $f_{2}$-values, Table 4$)$ were present between SA1C1 and SA0.5C1, SA1C1 and SA0.75C1 as well as SA1M1 and SA0.75M1. In addition, comparisons between formulations of the same lipid:drug ratios but different filler combinations for stearic acid also revealed statistically significant differences, signifying that the filler type, together with the lipid:drug ratio, were instrumental in drug release (Supplementary Material, Table S6).

Table 4. Release kinetics of artemether from lipid matrix tablets in sequential dissolution media, including biorelevant components, according to different mathematical models and fit factor values versus the release kinetics of Coartem ${ }^{\circledR}$.

\begin{tabular}{|c|c|c|c|c|c|c|c|c|}
\hline \multirow{2}{*}{ Formulation } & \multirow{2}{*}{ MDT } & \multicolumn{2}{|c|}{ Fit Factors } & \multicolumn{3}{|c|}{ Goodness of Fit } & \multicolumn{2}{|r|}{ Best-Fit Values } \\
\hline & & $f_{1}$ & $f_{2}$ & Rsqr adj & AIC & MSC & $\mathrm{T}_{\text {lag }}$ & Model Variable \\
\hline SA $0.5 \mathrm{M} 11^{a}$ & 310.500 & 30.674 & 43.502 & 0.9899 & 97.517 & 3.803 & 120.000 & $\mathrm{k}_{\mathrm{KP}}: 8.98 ; \mathrm{n}: 0.37$ \\
\hline $\mathrm{SA} 0.5 \mathrm{C} 1^{\mathrm{a}}$ & 315.000 & 20.247 & 50.338 & 0.9847 & 104.317 & 3.402 & 120.000 & $\mathrm{k}_{\mathrm{KP}}: 8.114 ; \mathrm{n}: 0.385$ \\
\hline SA $0.75 \mathrm{M} 1 \mathrm{~b}$ & 382.400 & 39.821 & 38.111 & 0.9712 & 111.122 & 2.743 & 120.000 & $\mathrm{k}_{1}: 4.398 ; \mathrm{k}_{2}: 2.216 ; \mathrm{m}: 0.261$ \\
\hline SA $0.75 C 1^{b}$ & 315.500 & 19.180 & 49.743 & 0.9927 & 92.358 & 4.091 & 120.000 & $\mathrm{k}_{1}: 8.131 ; \mathrm{k}_{2}: 2.486 ; \mathrm{m}: 0.244$ \\
\hline $\mathrm{SA} 1 \mathrm{M} 1^{\mathrm{c}}$ & 374.000 & 29.238 & 42.157 & 0.9978 & 69.193 & 5.464 & 120.000 & $\mathrm{k}_{1}: 2.704 ; \mathrm{k}_{2}: 0.047$ \\
\hline $\mathrm{SA} 1 \mathrm{C} 1^{\mathrm{c}}$ & 386.500 & 43.479 & 35.107 & 0.9900 & 94.958 & 3.986 & 120.000 & $\mathrm{k}_{1}: 1.956 ; \mathrm{k}_{2}: 0.08$ \\
\hline GM0.5M1 ${ }^{\mathrm{a}}$ & 355.800 & 50.274 & 32.880 & 0.9968 & 76.064 & 5.094 & 130.442 & $\mathrm{k}_{\mathrm{KP}}: 3.264 ; \mathrm{n}: 0.528$ \\
\hline GM0.5C $1^{\text {a }}$ & 323.100 & 80.552 & 22.248 & 0.9951 & 39.170 & 4.685 & 152.871 & $\mathrm{k}_{\mathrm{KP}}: 0.677 ; \mathrm{n}: 0.573$ \\
\hline GM0.75M1 c & 499.400 & 66.135 & 25.610 & 0.9981 & 54.831 & 5.756 & 349.090 & $\mathrm{k}_{1}: 4.403 ; \mathrm{k}_{2}:-0.051$ \\
\hline GM0.75C $1^{a}$ & 350.800 & 28.360 & 43.340 & 0.9956 & 81.279 & 4.718 & 120.000 & $\mathrm{k}_{\mathrm{KP}}: 4.305 ; \mathrm{n}: 0.481$ \\
\hline GM1M1 c & 313.000 & 45.026 & 32.888 & 0.9990 & 59.719 & 6.239 & 165.510 & $\mathrm{k}_{1}: 5.997 ; \mathrm{k}_{2}:-0.075$ \\
\hline GM1C1 $b$ & 310.900 & 42.262 & 34.766 & 0.9920 & 93.219 & 4.026 & 117.890 & $\mathrm{k}_{1}: 10.179 ; \mathrm{k}_{2}: 0.823 ; \mathrm{m}: 0.285$ \\
\hline CA $0.5 \mathrm{M} 11^{\mathrm{a}}$ & 407.200 & 65.595 & 26.848 & 0.9719 & 85.176 & 2.971 & 45.934 & $\mathrm{k}_{\mathrm{KP}:} 0.035 ; \mathrm{n}: 1.098$ \\
\hline CA $0.5 \mathrm{C} 1^{\mathrm{b}}$ & 341.000 & 30.807 & 40.008 & 0.9978 & 72.708 & 5.387 & 150.000 & $\mathrm{k}_{1}: 4.199 ; \mathrm{k}_{2}: 2.153 ; \mathrm{m}: 0.279$ \\
\hline CA $0.75 \mathrm{M} 11^{a}$ & 454.100 & 73.660 & 24.011 & 0.9957 & 71.334 & 4.935 & 265.246 & $\mathrm{k}_{\mathrm{KP}}: 0.570 ; \mathrm{n}: 0.793$ \\
\hline $\mathrm{CA} 0.75 \mathrm{C} 1^{\mathrm{c}}$ & 358.000 & 31.522 & 39.295 & 0.9988 & 60.730 & 6.066 & 150.000 & $\mathrm{k}_{1}: 3.456 ; \mathrm{k}_{2}: 0.026$ \\
\hline $\mathrm{CA} 1 \mathrm{M} 1^{\mathrm{a}}$ & 285.300 & 23.989 & 42.616 & 0.9961 & 83.323 & 4.7571 & 150.000 & $\mathrm{k}_{\mathrm{KP}}: 18.868 ; \mathrm{n}: 0.256$ \\
\hline $\mathrm{CA} 1 \mathrm{C} 1^{\mathrm{c}}$ & 472.900 & 72.880 & 24.405 & 0.9885 & 75.041 & 3.913 & 240.000 & $\mathrm{k}_{1}: 1.469 ; \mathrm{k}_{2}: 0.034$ \\
\hline
\end{tabular}

${ }^{\text {a }}$ Korsmeyer-Peppas with $\mathrm{T}_{\text {lag }} ;{ }^{\mathrm{b}}$ Peppas-Sahlin1with $\mathrm{T}_{\text {lag }} ;{ }^{\mathrm{c}}$ Peppas-Sahlin2 with $\mathrm{T}_{\text {lag. }} ; \mathrm{k}_{1}$ = diffusion constant; $\mathrm{k}_{2}$ = relaxation constant; $\mathrm{m}=$ diffusion exponent; $\mathrm{n}=$ drug release exponent; $\mathrm{k}_{\mathrm{KP}}=$ release constant. 

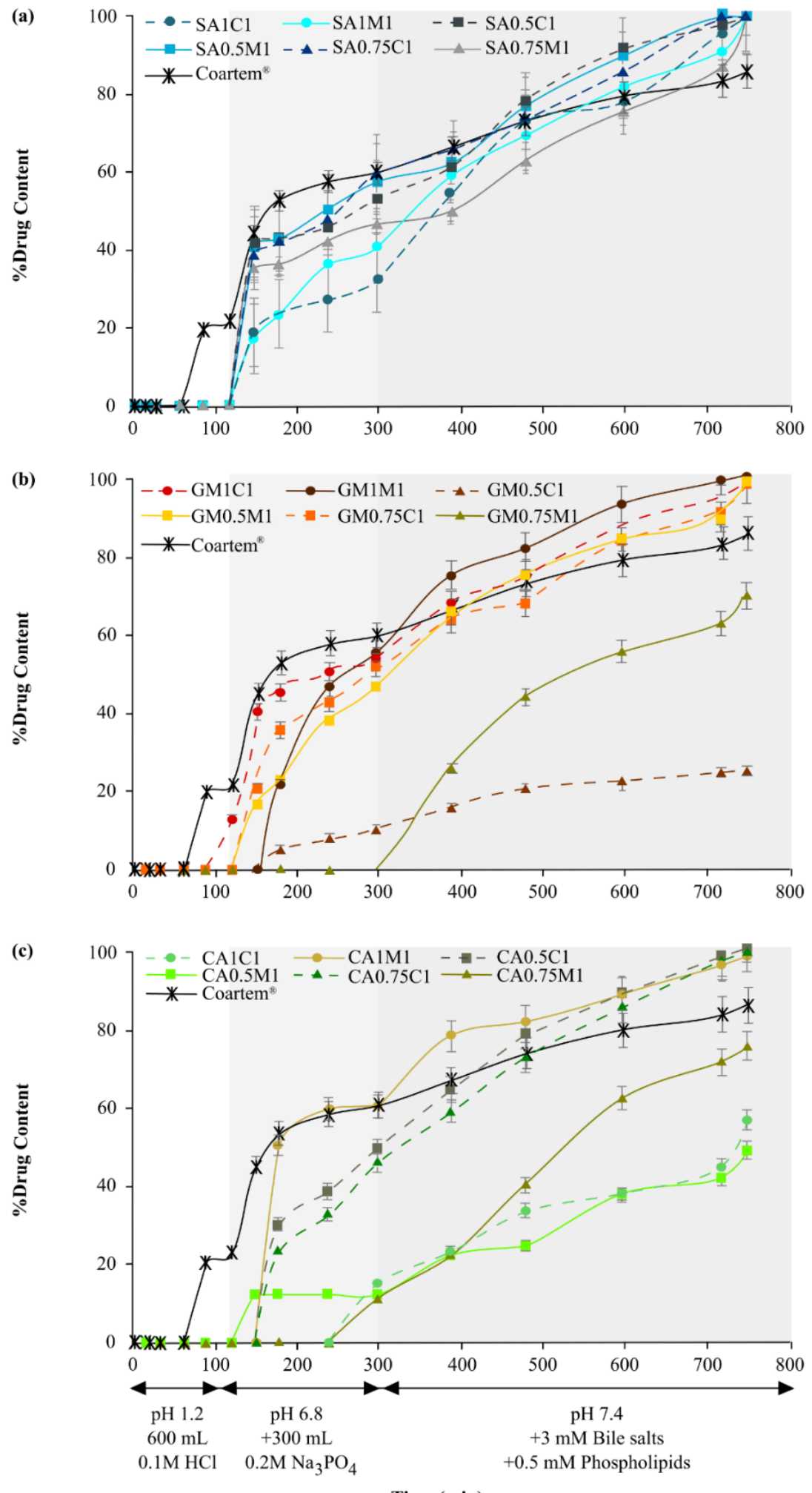

Figure 2. Effect of the inclusion of sequential dissolution media during dissolution behavior studies on the artemether release profiles for the respective (a) stearic acid, (b) glycerol monostearate and (c) cetyl alcohol formulations. The shaded areas and annotations denote the time-points for the changes in dissolution media $(n=6)$.

Glycerol monostearate containing lipid matrix tablet formulations displayed the highest variance in lag time, as well as percentage of artemether released between the respective 
formulations when compared to stearic acid lipid bases (Figure 2b). GM0.75M1 specifically displayed release characteristics dependent upon the presence of the biorelevant media. GM1M1 also stressed the influence of biorelevant media, as there are two distinct spikes in drug release: first, when the $\mathrm{pH}$ was increased $(120 \mathrm{~min})$, and second, with the addition of biorelevant media (300 min). All glycerol monostearate containing formulations displayed statistically relevant differences $(p<0.05)$ when compared (Table 4; Supplementary Material, Table S6). They additionally portrayed the lowest average mean dissolution times of the lipid bases, denoting that they possessed the least artemether release retardation properties. GM0.5M1 and GM0.5C1 did, however, not adhere to the acceptance criteria for the percentage of artemether released [25], as these formulations only released $63.49 \%$ and $36.71 \%$ artemether, respectively.

No specific overall trend in artemether release profiles for formulations comprising glycerol monostearate could be defined. Nonetheless, GM0.5C1, GM0.5M1 and GM0.75C1 all depicted non-Fickian diffusion, fitting the Korsmeyer-Peppas with $\mathrm{T}_{\text {lag }}$ model (Table 4). The process of non-Fickian diffusion is mainly observed when the temperature is below that of glass transitioning, meaning that the polymer chains are not sufficiently mobile to permit immediate solvent penetration into the polymer core. This may be as a result of the solid lipid dispersions being prepared below their glass transition temperatures, as explained in previous work by the authors [10]. GM0.75M1 and GM1M1 followed the Peppas-Sahlin2 with $\mathrm{T}_{\text {lag }}$ model, whilst GM1C1 fitted the Peppas-Sahlin1 with $\mathrm{T}_{\text {lag }}$ model, also signifying non-Fickian diffusion (Table 4).

Cetyl alcohol formulations with MicroceLac ${ }^{\circledR} 100$ as filler best fitted the KorsmeyerPeppas with $\mathrm{T}_{\text {lag }}$ model. CA1M1 portrayed Fickian diffusion with prominent polymer relaxation (Figure 3b). Additionally, CA1M1 depicted burst release (approximately 50\%) once lag time had elapsed (Figure 2c). CA0.5M1 showed super case II transport and CA0.75M1 was classified as non-Fickian diffusion, as per the n-values. It is therefore clear that the lipid:drug ratio determined the mechanism of drug release associated with the Korsmeyer-Peppas with $\mathrm{T}_{\text {lag }}$ model. Cetyl alcohol-CombiLac ${ }^{\circledR}$ formulations (CA1C1 and CA0.75C1) exhibited artemether dissolution in accordance with the Peppas-Sahlin2 with $\mathrm{T}_{\text {lag }}$ model, whilst CA0.5C1 fitted the Peppas-Sahlin1 with $\mathrm{T}_{\text {lag }}$ model.

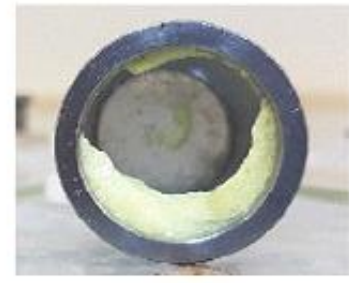

(a)

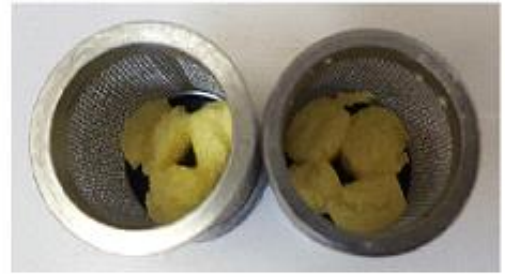

(b)

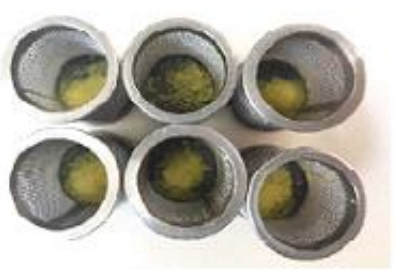

(c)

Figure 3. Visual representation of (a) hypromellose gel matrix formed by Coartem ${ }^{\circledR}$; (b) example of relatively intact formulated lipid matrix tablets produced in this study after $750 \mathrm{~min}$ dissolution, highlighting the effect of polymer relaxation; and (c) example of formulated lipid granules that once contained active pharmaceutical ingredient particles within lipid matrix tablets, demonstrating erosion release dissolution profiles.

Cetyl alcohol comprising formulations presented the highest average mean dissolution time values of the three lipid bases, indicating that this lipid base retarded drug release the most (Figure 2c). The effect of the presence of biorelevant media is perhaps most pronounced when considering formulation CA0.5M1, where it is clear that artemether release was constant after an increase in $\mathrm{pH}$ (to that simulating small intestine $\mathrm{pH}$ ) prior to the addition of biorelevant media. CA0.5M1 and CA1C1 did not meet the acceptance criteria for percentage artemether release, as they both released less than $60 \%$ of the artemether content [25]. Cetyl alcohol-CombiLac ${ }^{\circledR}$ formulations exhibited similar release profiles in terms of sustained release, and this similarity was confirmed by the fit factors (Supplementary Material, Table S6). CA0.5C1 versus CA0.75C1 attained an $\mathrm{f}_{1}$-value of 
4.584 and an $\mathrm{f}_{2}$-value of 82.168 , signifying that no statistical differences were present, which coincides with these two formulations exhibiting the same lag time (150 min). However, significant differences existed between CA1C1 and the formulations CA0.5C1 and $\mathrm{CA} 0.75 \mathrm{C} 1$, respectively, which can be explained by the difference in lag time, namely CA1C1 displayed initial drug release at $240 \mathrm{~min}$, whereas both CA0.5C1 and CA0.75C1 showed signs of drug release of more than $20 \%$ at $180 \mathrm{~min}$.

The inclusion of biorelevant media proved most valuable and their effects are significant. Their influence was most pronounced when considering cetyl alcohol formulations, as highlighted by an $R^{2}$-value of 0.737 prior to their inclusion, and a subsequent $R^{2}$-value of 0.969 thereafter. In other words, their inclusion rendered near-linear drug release. This effect was true for all three lipid bases.

Coartem ${ }^{\circledR}$ comprises polysorbate 80 (a surfactant), as well as hypromellose and microcrystalline cellulose, as fillers. The presence of a surfactant, together with the gel matrix forming properties of Hypromellose, made for interesting comparisons pertaining to the percentage artemether released and the dissolution release kinetics. It was notably clear that polysorbate 80 was able to provide sufficient wetting of artemether at a lower $\mathrm{pH}$ of 1.2, allowing for its earlier detection comparably. Moreover, an increase in $\mathrm{pH}$ to 6.8 coincided with a prominent spike in artemether release from this product. Coartem ${ }^{\circledR}$ fitted the Peppas-Sahlin 2 with $\mathrm{T}_{\text {lag }}$ model, which is explained by the erosion of the tablet (visible within the first $2 \mathrm{~min}$ of dissolution testing) and diffusion of artemether from the gel matrix formed by the Hypromellose, as seen in Figure 3a.

During the dissolution experiments performed, lumefantrine could not be quantified for either the formulated lipid matrix tablets or the commercial product, Coartem ${ }^{\circledR}$. Lumefantrine has a distribution coefficient (log $\mathrm{D}$ value) of 8.9 and 10.1 at $\mathrm{pH} 6$ and 7.4, respectively [45]. This value reflects the distribution of a drug between an organic phase and a water phase. The considerably high $\log \mathrm{D}$ values of lumefantrine define its affinity for an organic or lipophilic phase and provide a fundamental explanation for the absence of its detection during the dissolution studies conducted. Additionally, it was clear that the concentration and type of phospholipid included in the sequential dissolution media was insufficient to increase lumefantrine wettability to such an extent so as to produce a high enough concentration present in the water phase for detection.

To summarize, stearic acid comprising formulations provided the most consistent modified artemether release profiles, with a predictable lag time of $180 \mathrm{~min}$. The inherent surfactant properties of stearic acid proved beneficial and resulted in the consistently highest initial percentage of artemether released, in conjunction with an increase in $\mathrm{pH}$ from 1.2 to 6.8. Thus, this lipid base was selected as optimal for the formulation of lipid matrix tablets comprising artemether. On the other hand, glycerol monostearate formulations depicted greater variances in lag times and illustrated inadequate artemether release profiles comparatively. Of the two fillers incorporated, CombiLac ${ }^{\circledR}$ yielded more formulations capable of releasing the required artemether content compared to MicroceLac ${ }^{\circledR} 100$. Additionally, these formulations exhibited less variance in lag times. With regard to lipid:drug ratio, the 0.75:1 ratio faired favorably, as it delivered acceptable artemether amounts released for all formulations bar one $(70.36 \%)$. However, in totality, SA $0.5 \mathrm{C} 1$ bore an ideal percentage of artemether released $(97.21 \%)$, according to assay value versus theoretical content. This formulation furthermore displayed the most optimal pharmacotechnical properties, taking the formulation factors and corresponding responses into account, and it may therefore be resolved that it is the most promising formulation of the investigated candidates pertaining to the pharmacotechnical properties, as well as to artemether release kinetics. In addition, when utilizing highly lipophilic active pharmaceutical ingredients, biorelevant media is of immense value and a worthwhile inclusion necessary to more accurately predict lipophilic drug release, given the more realistic physiologically mimicked environment provided.

As stated, this study focused on investigating the effect of hot fusion on augmenting dissolution, together with the significance of biorelevant media for these tested active pharmaceutical ingredients. It in no way set out to perfect a dissolution media environ- 
ment optimal for the concurrent evaluation of artemether and lumefantrine. This study rather aimed to establish whether the broad, proposed simulated gastric media was specific enough to handle the unique needs of artemether and lumefantrine quantification. This study found that whilst simulated gastric media is recommended, specific method development is still required for extremely lipophilic compounds such as lumefantrine as lumefantrine release could not be detected in the dissolution media and therefore no dissolution profiles could be drawn. The general method proposed for lipophilic compounds was only successful for the detection of artemether. A discriminatory method alone, though useful, is still less than ideal due to the lack of in vivo linkage [46]. Unfortunately, when delving into method development, situations will exist that do not have quantitative relevance to all formulation variables. This study applied a broad and simplified simulated gastric media to establish the relevance of biorelevant media and to investigate the proposed dissolution method adjustments without imposing too many restrictions.

The addition of biorelevant media was vital and considerably increased the release of artemether from the lipid matrix tablets manufactured. However, the basic composition of the biorelevant media utilized lacked characteristics capable of solubilizing lumefantrine to such an extent that it could be quantitatively detected employing HPLC for the formulations manufactured during this study, or for the commercial product, Coartem ${ }^{\circledR}$. This speaks to the unique needs and high lipophilicity of lumefantrine rather than to an inadequacy of biorelevant media.

\subsection{In Vitro Permeability Studies}

Permeability studies of the identified optimal formulation (SA0.5C1) were conducted as a proof of concept, and revealed a lack of specificity for the model used. To date, and to the best of our knowledge, highly lipophilic drugs incorporated into lipid-based formulations have yet to be tested extensively on the in vitro permeability model investigated. The primary drawback of diffusion chambers, specifically Ussing chambers or Sweetana-Grass diffusion chambers, is the underestimation of drug transport, particularly for lipophilic compounds [47].

The shortcomings of this model proved problematic. Only after a number of adjustments, including the addition of bile salts and phospholipids to the apical chamber to simulate the systemic environment and minimizing the dilution factor, could the conduction of a single endpoint analysis yield detection of both artemether $(3.35 \%)$ and lumefantrine $(4.88 \%)$ transport in the basolateral chambers. The overall average percentage of TEER reduction at time $120 \mathrm{~min}$ was $7.09 \%$, indicating that the tight junctions were not opened and the tissue integrity remained intact and viable. Further ex vivo analysis of the tissue revealed $9.88 \%$ artemether and 59.56\% lumefantrine drug retention within the tissue, which additionally served as an indication that both artemether and lumefantrine were released in quantifiable concentrations from the lipid matrix tablet formulation.

These results are by no means ideal. However, they do highlight the need for the development of an in vitro model suited to the specific needs of lipid-based formulations and make for interesting future prospects capable of decreasing the use of animals in research [48], whilst simultaneously providing the researcher with a more accurate permeability model for the evaluation of lipid-based formulations.

\section{Conclusions}

This study validates the feasibility of manufacturing lipid matrix tablets from solid lipid dispersions prepared by means of hot fusion. The production method employed temperatures below the melting point and glass transitioning temperatures of the active pharmaceutical ingredients, thereby only proving a lipid coating of the drugs and a lipidic microenvironment for artemether and lumefantrine to theoretically partition into during drug dissolution. Dissolution behavior testing demonstrated that the addition of biorelevant media resulted in a spike in the artemether concentration, highlighting their relevance when testing highly lipophilic active pharmaceutical ingredients. Moreover, the 
percentage of artemether release from the formulated lipid matrix tablets was found to be higher compared to that of the commercially available product, Coartem ${ }^{\circledR}$, under the same experimental conditions. Thus, this study has provided evidence to support the plausibility of utilizing hot fusion technology to significantly augment the solubility of the antimalarial drugs analyzed, which so often fail based purely on varied bioavailability stemming from poor aqueous solubility. This, coupled with the demonstrated capability to formulate a solid oral dosage form with modified drug release, could therefore provide malaria treatment with a much-needed answer to treatment failure and the emergence of drug resistance.

Supplementary Materials: The following data are available online at https://www.mdpi.com/ article/10.3390/pharmaceutics13070922/s1, Table S1: Average values obtained for the physical properties (mass variation presented as \%RSD in parenthesis) of the lipid matrix tablet formulations containing either MicroceLac ${ }^{\circledR}$ or CombiLac ${ }^{\circledR}$ as filler. Values highlighted and in bold indicate that the formulation did not adhere to the criteria for the specific experiment, Table S2: Average values obtained for the physical properties (mass variation presented as \%RSD in parenthesis) of the lipid matrix tablet formulations containing either Pharmace ${ }^{\circledR} 101$ or RetaLac ${ }^{\circledR}$ as filler. Values highlighted and in bold indicate that the formulation did not adhere to the criteria for the specific experiment, Table S3: Comparison of all formulation factors, including RetaLac ${ }^{\circledR}$ and Pharmacel ${ }^{\circledR} 101$ fillers, investigated in the full factorial design regarding average mass variation, friability and tensile strength results to demonstrate the negative effect of these fillers on reporting, Table S4: Abbreviations allocated to formulations, Figure S1: Morphology photographs showing (i) external and (ii) internal surfaces for formulations (a) SA0.5M1; (b) SA0.5C1; (c) SA0.75M1; (d) SA0.75C1; (e) SA1M1; and (f) SA1C1, Figure S2: Morphology photographs showing (i) external and (ii) internal surfaces for formulations (a) GM0.5M1; (b) GM0.5C1; (c) GM0.75M1; (d) GM0.75C1; (e) GM1M1; and (f) GM1C1, Figure S3: Morphology photographs showing (i) external and (ii) internal surfaces for formulations (a) CA0.5M1; (b) CA0.5C1; (c) CA0.75M1; (d) CA0.75C1; (e) CA1M1; and (f) CA1C1, Figure S4: Morphology photographs showing (i) top view and (ii) side view of tablets for selected formulations (a) GM0.5P1; (b) GM0.5P1.25; (c) GM0.75P1; (d) GM0.75P1.25; (e) GM1P1; (f) GM1P1.25 (g) GM0.75R1 and (h) GM0.75R1.25; where P signifies Pharmace ${ }^{\circledR} 101$ and R signifies RetaLac ${ }^{\circledR}$, Table S5: \%API content determined per formulation, Table S6: Fit factors analyzed indicating statistically significant differences in green and similarities in red.

Author Contributions: Conceptualization, J.M.V. and L.H.d.P.; methodology, J.M.V. and C.A.W.; software, C.A.W.; validation, J.M.V., C.A.W. and L.H.d.P.; formal analysis, C.A.W. and J.M.V.; investigation, C.A.W.; resources, J.M.V.; data curation, C.A.W. and J.M.V.; writing-original draft preparation, C.A.W.; writing-review and editing, J.M.V. and C.A.W.; visualization, J.M.V. and C.A.W.; supervision, J.M.V. and L.H.d.P.; project administration, J.M.V.; funding acquisition, J.M.V. and L.H.d.P. All authors have read and agreed to the published version of the manuscript.

Funding: This research did not receive any specific grant from funding agencies in the public, commercial or not-for-profit sectors.

Institutional Review Board Statement: The study was conducted according to the guidelines of the Declaration of Helsinki. Ethical approval for the procurement of excised porcine jejunum segments from a local abattoir was obtained from the Health Research Ethics Committee (HREC), North-West University (NWU), South Africa, on 7 December 2016 (approval number: NWU-00369-16-A1).

Informed Consent Statement: Not applicable.

Data Availability Statement: Not applicable.

Conflicts of Interest: The authors declare no conflict of interest.

\section{References}

1. The World Health Organization. World Malaria Report. Available online: https://www.who.int/news-room/feature-stories/ detail/world-malaria-report-2019 (accessed on 14 December 2019).

2. Khuda, F.; Iqbal, Z.; Shah, Y.; Ahmmad, L.; Nasir, F.; Khan, A.Z.; Shahbaz, N. Method development and validation for simultaneous determination of lumefantrine and its major metabolite, desbutyl lumefantrine in human plasma using RPHPLC/UV detection. J. Chromatogr. B 2014, 944, 114-122. [CrossRef] 
3. Lindenberg, M.; Kopp, S.; Dressmann, J.B. Classification of orally administered drugs on the World Health Organization model list of essential medicines according to the biopharmaceutical classification system. Eur. J. Pharm. Biopharm. 2004, 58, 265-278. [CrossRef]

4. Van, V.M.; Brockman, A.; Gemperli, B. Randomized comparison of artemether benflumetol and artesunate-mefloquine in treatment of multidrug-resistant falciparum malaria. Antimicrob. Agents Chemother. 1998, 42, 135-139. [CrossRef]

5. Ambike, A.A.; Mahadik, K.R.; Paradkar, A. Stability study of amorphous valdecoxib. Int. J. Pharm. 2004, 282, 151-162. [CrossRef] [PubMed]

6. Feeney, O.M.; Crum, M.F.; McEvoy, C.L.; Trevaskis, N.L.; Williams, H.D.; Pouton, C.W.; Charman, W.N.; Bergström, C.A.S.; Porter, C.J.S. 50 years of oral lipid-based formulations: Provenance, progress and future perspectives. Adv. Drug Deliv. Rev. 2016, 101, 167-194. [CrossRef]

7. Hofmann, A.F.; Borgström, B. The intraluminal phase of fat digestion in man: The lipid content of the micellar and oil phases of intestinal content obtained during fat digestion and absorption. J. Clin. Investig. 1964, 43, 247-257. [CrossRef] [PubMed]

8. Humberstone, A.J.; Porter, C.J.H.; Charman, W.N. A physiological basis for the effect of food on the absolute oral bioavailability of halofantrene. J. Pharm. Sci. 1996, 85, 525-529. [CrossRef]

9. Porter, C.J.H.; Pouton, C.W.; Cuine, J.F.; Charman, W.N. Enhancing intestinal drug solubilisation using lipid-based delivery systems. Adv. Drug Deliv. Rev. 2008, 60, 673-691. [CrossRef]

10. Wilkins, C.A.; du Plessis, L.H.; Viljoen, J.M. Characterization of solid lipid dispersions prepared by hot fusion containing a double-fixed dose combination of artemether and lumefantrine. Drug Dev. Ind. Pharm. 2020, 46, 1289-1297. [CrossRef]

11. Mu, H.; Holm, R.; Müllertz, A. Lipid-based formulations for oral administration of poorly water-soluble drugs. Int. J. Pharm. 2013, 453, 215-224. [CrossRef] [PubMed]

12. Blagden, N.; de Matas, M.; Gavan, P.T.; York, P. Crystal engineering of active pharmaceutical ingredients to improve solubility and dissolution rates. Adv. Drug Deliv. Rev. 2007, 59, 617-633. [CrossRef]

13. Corrigan, O.I. Mechanisms of dissolution of fast release solid dispersions. Drug Dev. Ind. Pharm. 1985, 11, 697-724. [CrossRef]

14. Hancock, B.C.; Parks, M. What is the true solubility advantage for amorphous pharmaceuticals? Pharm. Res. 2000, 17, 397-404. [CrossRef]

15. Hancock, B.C.; Zografi, G. Characteristics and significance of the amorphous state in pharmaceutical systems. J. Pharm. Sci. 1997, 86, 1-12. [CrossRef]

16. Janssens, S.; van den Mooter, G. Review: Physical chemistry of solid dispersions. J. Pharm. Pharmacol. 2009, 61, 1571-1586. [CrossRef]

17. Edueng, K.; Mahlin, D.; Bergström, C.A.S. The need of restructuring the disordered science of amorphous drug formulations. Pharm. Res. 2017, 34, 1754-1772. [CrossRef]

18. Jantratid, E.; Janssen, N.; Reppas, C.; Dressman, J.B. Dissolution media simulating conditions in the proximal human gastrointestinal tract: An update. Pharm. Res. 2008, 25, 1663-1675. [CrossRef]

19. Kleberg, K.; Jacobsen, J.; Müllertz, A. Characterising the behaviour of poorly water soluble drugs in the intestine: Application of biorelevant media for solubility, dissolution and transport studies. J. Pharm. Pharmacol. 2010, 62, 1656-1668. [CrossRef]

20. Zoeller, T.; Klein, S. Simplified biorelevant media for screening dissolution performance of poorly soluble drugs. Dissolut. Technol. 2007, 14, 8-13. [CrossRef]

21. Sunesen, V.H.; Pedersen, B.L.; Kristensen, H.G.; Müllertz, A. In vivo in vitro correlations for a poorly soluble drug, danazol, using the flow-through dissolution method with biorelevant dissolution media. Eur. J. Pharm. Sci. 2005, 24, 305-313. [CrossRef]

22. Wang, Q.; Fotaki, N.; Mao, Y. Biorelevant dissolution: Methodology and application in drug development. Dissolut. Technol. 2009, 16, 6-12. [CrossRef]

23. Obaidat, A.A.; Obaidat, R.M. Release of tramadol hydrochloride from matrices prepared using glyceryl behenate. Eur. J. Pharm. Biopharm. 2001, 52, 231-235. [CrossRef]

24. Özyazici, M.; Gökçe, E.H.; Ertan, G. Release and diffusional modelling of metronidazole lipid matrices. Eur. J. Pharm. Biopharm. 2006, 63, 331-339. [CrossRef] [PubMed]

25. British Pharmacopoeia. Available online: https://www.pharmacopoeia.com/ (accessed on 23 February 2021).

26. Shang, C.; Sinka, I.C.; Jayaraman, B.; Pan, J. Break force and tensile strength relationships for curved faced tablets subject to diametrical compression. Int. J. Pharm. 2013, 442, 57-64. [CrossRef]

27. Costa, C.; Nogueira, F.H.A.; Pianetti, G.A. Simultaneous determination of artemether and lumefantrine in fixed dose combination tablets by HPLC with UV detection. J. Pharm. Biomed. Anal. 2008, 48, 951-954. [CrossRef]

28. Obitte, N.C.; Chukwu, A.; Onyishi, I.V. The use of a pH-dependent and non pH-dependent natural hydrophobic biopolymer (Landolphia owariensis latex) as capsule coating agents in in vitro controlled release of metronidazole for possible colon targeted delivery. Int. J. Appl. Res. Nat. Prod. 2010, 3, 1-17. [CrossRef]

29. Vertzoni, M.; Fotaki, N.; Kostewicz, E.; Stippler, E.; Leuner, C.; Nicolaides, E.; Dressman, J.; Reppas, C. Dissolution media simulating the intraluminal composition of the small intestine: Physiological issues and practical aspects. J. Pharm. Pharmacol. 2004, 56, 453-462. [CrossRef] [PubMed]

30. Zhang, Y.; Huo, M.; Zhou, J.; Zou, A.; Li, W.; Yao, C.; Xie, S. DDSolver: An add-in program for modelling and comparison of drug dissolution profiles. AAPS J. 2010, 12, 263-271. [CrossRef] 
31. Costa, F.O.; Sousa, J.J.S.; Pais, A.A.C.C.; Formosinho, S.J. Comparison of dissolution profiles of Ibuprofen pellets. J. Control. Release 2003, 89, 199-212. [CrossRef]

32. Moore, J.W.; Flanner, H.H. Mathematical comparison of dissolution profiles. Pharm. Technol. 1996, 20, 64-74. [CrossRef]

33. Costa, P.; Lobo, J.M.S. Modelling and comparison of dissolution profiles. Eur. J. Pharm. Sci. 2001, 13, 123-133. [CrossRef]

34. Hansen, T.S.; Nilsen, O.G. Echinacea purpurea and P-glycoprotein drug transport in Caco-2 cells. Phytother. Res. 2009, $23,86-91$. [CrossRef] [PubMed]

35. Hellum, B.H.; Nilsen, O.G. In vitro inhibition of CYP3A4 metabolism and P-Glycoprotein-mediated transport by trade herbal products. Basic Clin. Pharmacol. Toxicol. 2008, 102, 466-475. [CrossRef] [PubMed]

36. Adeleye, O.A.; Femi-Oyewo, M.N.; Odeniyi, M.A. Effect of compression pressure on mechanical and release properties of tramadol matrix tablets. Curr. Issues Pharm. Med. Sci. 2015, 28, 120-125. [CrossRef]

37. Sheskey, P.J.; Robb, R.T.; Moore, R.D.; Boyce, B.M. Effects of lubricant level, method of mixing, and duration of mixing on a controlled-release matrix tablet containing hydroxypropyl methylcellulose. Drug Dev. Ind. Pharm. 1995, 21, 2151-2165. [CrossRef]

38. Podczeck, F.; Miah, Y. The influence of particle size and shape on the angle of internal friction and the flow factor of unlubricated and lubricated powders. Int. J. Pharm. 1994, 144, 187-194. [CrossRef]

39. Sabir, A.; Evans, B.; Jain, S. Formulation and process optimization to eliminate picking from market image tablets. Int. J. Pharm. 2001, 215, 123-135. [CrossRef]

40. Yamamura, T.; Ohta, T.; Taira, T.; Ogawa, Y.; Sakai, Y.; Moribe, K.; Yamamoto, K. Effects of automated external lubrication on tablet properties and the stability of eprazinone hydrochloride. Int. J. Pharm. 2009, 370, 1-7. [CrossRef]

41. Bossert, J.; Stamm, A. Effect of mixing on the lubrication of crystalline lactose by magnesium stearate. Drug Dev. Ind. Pharm. 1980, 6, 573-589. [CrossRef]

42. Dansereau, R.; Peck, G.E. The effect of the variability in the physical and chemical properties of magnesium stearate on the properties of compressed tablets. Drug Dev. Ind. Pharm. 1987, 64, 51-65. [CrossRef]

43. Bolhuis, G.K.; Hollzer, A.W. Lubricant sensitivity. In Pharmaceutical Powder Compaction Technology; Alderborn, G., Nystrom, C., Eds.; Marcel Dekker: New York, NY, USA, 1996; pp. 517-560.

44. Kikuta, J.; Kitamori, N. Effect of mixing time on the lubrication properties of magnesium stearate and the final characteristics of the compressed tablets. Drug Dev. Ind. Pharm. 1994, 20, 343-355. [CrossRef]

45. Schlagenhauf-Lawlor, P. Travellers' Malaria, 2nd ed.; BC Decker Inc.: Ontario, CA, USA, 2008; pp. 1-388.

46. Gray, V.A. Power of the dissolution test in distinguishing a change in dosage form critical quality attributes. AAPS PharmSciTech 2018, 19, 3328-3332. [CrossRef] [PubMed]

47. Nunes, R.; Silva, C.; Chaves, L. Tissue-Based In Vitro and Ex Vivo Models for Intestinal Permeability Studies. 2016. Available online: http:/ / dx.doi.org/10.1016/B978-0-08-100094-6.00013-4 (accessed on 24 November 2019).

48. Pampaloni, F.; Reynaud, E.G.; Stelzer, E.H.K. The third dimension bridging the gap between cell culture and live tissue. Nat. Rev. Mol. Cell Biol. 2007, 8, 839-845. [CrossRef] [PubMed] 